\title{
CHANGING ECONOMIC TRENDS IN COMPETITION POLICY AND THE NEED FOR AN OPTIMUM COMPETITION POLICY IN CUSTOMS UNION WITH EUROPEAN UNION
}

ESRA LAGRO*

\section{Abstract}

Competition laws and policy, which integrate political, economical, legal, and even social aspects of a society, constitute a challenging dimension in the field of industrial organization. The article, first, defines the term competition and questions whether there is a tenable economic case for competition policy or not. Second, the three main economic paradigms which are still holding the agenda, in the field of industrial organization, and their function as policy alternatives in European Union and United States are discussed. Third, four main propositions for the purpose, scope and implementation of competition policy are presented. Fourth, the case of Turkey is considered with reference to the changing trends in the world and the customs union with European Union. Finally, the article highlights some main issues which should be taken into account during the process of creating a sound competition policy in Turkey.

Traditional Industrial Organization literature condemns monopolization and tries to prevent it. The main reason underlining this fact is that by way of monopolization, small number of firms could obtain power in basically two points. First, they can increase the price over the competitive level (meaning a decrease in production) and they can increase their profits. Second, they can use cheap input in the production so by decreasing their costs they might have higher profits. As it can be stated out from the above outlook, this freedom of action attained through monopolization increases the profits of the firms whereas, consumers are effected in a negative way. De- 
pending on these reasons, governmental authorities are against the monopolization of firms and they try to impose certain regulations and enact laws which are commonly known as "antitrust laws". In EU, the basic legal basis for the competition (antitrust) policy is the articles 85 and 86 of the Rome Treaty and the regulations issued by the European Commission and in Turkey, the Competition Act which was accepted by the Parliament on December 7th, 1994. During the preparation of the Competition Act of Turkey EU competition policy has been taken as a model and this partially owes to Turkey's efforts to harmonize her laws and regulations with EU on the eve of Customs Union.

On the other hand, starting from 1970 s on, especially economists of Chicago School (Demsetz, Brozen, Peltzman) claimed that the monopolization and the profits originating from it are not necessarily due to anticompetitive prices but are due to the cost reductions through efficient resource allocation. Therefore, they underlined the fact that antitrust regulations against monopolization should be reconsidered. Starting from 1980s on, this approach is believed to be widely accepted and the antitrust regulations are minimized in United States.

Competition laws and policy have always been a challenging dimension in the field of industrial organization. It is unique in the sense that it merges political, legal and even social aspects into one big whole. Therefore, there is need for a better understanding of the term competition and its place in the history of economics, before proceeding through the changing trends in the world and the competitive effects of customs union with EU.

\section{The Meaning of Competition}

Competition is one of the fundamental principles of economic theory, and despite its profilic usage as a concept, it is believed to be misunderstood and often misused. The Thorndike dictionary defines competition as "contest, competing, trying to gain something for which others are trying at the same time". The word "competitive" again in the dictionary is written as "decided by competition, involving competition; having to do with competition". As it can be pointed out in the above definition, competition connotes rivalry between two or three people or groups for a given price.

It is known that there are two major historians of the concept of competition in economic theory, namely, Paul J.McNulty and George Stigler. According to Stigler, in economic life, competition is

"... a means of organizing economic activity to achieve a goal. The economic role of competition is to discipline the various participants in economic life to provide their goods and services skillfully and cheaply" (Stigler, 1968:5). 


\section{McNulty pointed out that competition is}

"... a principle so basic to economic reasoning that not even such powerful yet diverse critics of orthodox theory as Marx and Keynes could avoid relying upon it without ever clearly specifying what exactly, competition is" (McNulty, November 1968:639).

Both Stigler ${ }^{1}$ and McNulty ${ }^{2}$ share the same idea that the concept of competition has evolved from the emphasis of Adam Smith, in his Wealth of Nations, on rivalry between firms to competition as a situation where there is absence of effective monopoly power. In the Wealth of Nations, Smith did not deny that absence of entry barriers and collusion was necessary if there has to be meaningful rivalry yet he underlined the fact that the root of competition is noncollusive rivalry. Adam Smith thought the essence of competition was the actions of rival firms. Competition could be present even though there exists a monopoly power. In brief, noncollusive forms of rivalry, for instance, price cutting and product differentiation were competition according to Adam Smith (Stigler, Feb. 1957:1).

One view concerning competition is that it exists when there is no monopoly power. In other words, there should be no seller or buyer with price-making power and a remarkable effect upon market results. Absence of price-making ability is believed to be one of the key features of competition. The cutthroat pricing contests as the test of market strength between firms are considered to be a rivaliy.

The confusion between rivalry and competition is still an important issue in antitrust law. The term rivaliry in the modern sense refers to actual conduct and competition refers to a structurally determined ability to undertake certain behavior and conduct in the world.

\section{Is There a Tenable Economic Case for Competition Policy?}

There has been an ever continuing debate in the field of industrial organization concerning whether there is a tenable economic case for antitrust policy or not. As an answer to these question, many different paradigms are developed, but three of them are especially important and currently discussed. These are, namely, mainline paradigm, alternative paradigm, and the contestable market paradigm, and they will be presented rather briefly for the purposes of the present paper.

1 Stigler, G., "Perfect Compelition, Historically Contemplated", Journal of Economics, Feb. 1957, p.1-17.

2 McNulty, P., "A Note on the History of the Perfect Competition", Joumal of Political Economy, Aug. 1967, p.395-399. 


\subsection{The Mainline Paradigm :}

The mainline paradigm is associated with the names of economists like Edward Mason, Joe Bain, F.M. Scherer, Leonard Weiss, and William G. Shepherd. The mainline paradigm is also known as Structure-Conduct-Performance (SCP) yaradigm. The SCP paradigm has its roots in neoclassical theory, where competition is seen as a static concept and based on the perfect competition model. It is also important to note that the other paradigms came into existence as a criticism of the SCP paradigm. The causal relationship between the structure of a market, the conduct of the firms in the market, and their economic performance is the fundamental principle in this approach, and it is used as the theoretical background for industry policy, a typical area of which is competition policy. Structure relates to the importance and characteristics of individual markets within economy. This constitutes the meaning of the term in SCP approach (Ferguson, 1989:8). Structure can be identified by market concentration, that is, number and size distribution of buyers and sellers; the extent to which the products are differentiated; the barriers to entry; the diversification of the firms in the market, etc. These are some principal characteristics but it is known that there are more than twenty factors (McKie, 1970:9). Conduct refers to the actions of firms, moreover, to their decision-making process. The advertising, research and development, and to what limits to use them are among the features of conduct. The typical factors that are affecting conduct of the firms are often hard to examine empirically compared to structural and performance characteristics. For instance, structural aspects like market concentration could be empirically evaluated by way of mathematical testing. Moreover, the use of game theory starting from 1980s onwards for this purpose is a remarkable development especially from view point of oligopolistic markets. The economist's ultimate concern is with the performance of the firms (Ferguson, 1989:8). The question that is frequently asked is that whether the performance of firms help to increase the economic welfare or not. The answer to this question includes allocative efficiency, meaning the firm's production of the right good in the right quantity, and productive efficiency, that is optimal use of production factors, as well as price, cost and profit margins.

The attractiveness of the SCP approach mainly stems from the straightforward reasoning and the relative ease of identifying structural characteristics. The SCP approach is in need of finding solutions to identify different market structures for policy decisions. This follows that market concentration, in other words, the number and size distribution of firms with a market should be the focus of attention, and certain measures of market concentration should be known. However, one might also come across with the Austrian critique saying that these measures are redundant if competition is taken as a process. Yet many of the policy decisions and antitrust cases more or less depend on these measures. In brief, SCP emphasizes the role of struc- 
tural factors in facilitating collusion. Elevating prices, and generating supra-normal profits. The well-known implication of SCP approach provide a welfare theoretic basis for policies that attack collusion or the exercise of market power, or prevent substantial efforts to reach that power (Green, 1987:484).

\subsection{The Alternative Paradigm :}

Alternative paradigm, on the other hand, has been developed as a result of the criticisms against SCP paradigm. Contrary to the SCP approach, the alternative approach mainly takes into account the view that competition is a process rather than a state. In the 1970s and 1980s, economists recognized more and more the limitations of the traditional SCP approach which seemed far being an appropriate basis for policy decisions in the field of competition. The alternative paradigm is mainly associated with the economists at Chicago; Yale Brozen, Richard Posner, Sam Peltzman, UCLA; Harold Demsetz, and more recently Rochester; Liebowitz. The alternative approach provides an efficiency-superiority explanation for large market shares and for apparent supra-normal profitability of firms (Green, 1987:484). It explains a skewed size distribution of firms in terms of scale and non-scale differences in costs among firms. The non-scale differences arise from superiorities associated in particular with managerial factor, its capability in monitoring team production (Alchian and Demsetz, 1972:778). In brief, according to the followers of alternative approach, monopolization (or market power) cannot be blamed on its own, but one has to understand how firms develop monopolies. If the firms achieve a simpler mode of cost reduction as they grow, then, their profits also increase. This increase in profit is not the result of higher prices to the disadvantage of the consumer but from decrease in production costs. In this case, each monopolization will not result in the deterioration of the resource and income distribution but on the contrary, its improvement.

\subsection{The Contestable Market Theory :}

The most recent approach is the "contestable market theory", which is associated with the economists Baumol, Panzar, and Willig. In 1982, Baumol introduced his idea of "contestable markets". He stressed the fact that particular market structure is not necessarily equivalent of particular market performance. The contestable market theory postulates the industry conditions that result when entry into the market is absolutely free (though not costless, there are fixed costs). The followers of contestable market theory (Baumol, Panzar, Willig, and Bailey) focus on several aspects of entry but their results hold only for the following three conditions :

1. Entry is free and there are no limits: "Entrants can, without restriction, serve the same market demands and use the same productive techniques as those available to the incumbent firms" (Baumol, Panzar, Willig, 1982:5). 
2. Entry is absolute: the entrant can establish itself before an existing firm makes any price response.

3. Entry is perfectly reversible: exit is perfectly free and sunk cost is zero.

Contestability also requires that potential entrants can enter the market before already established firms could go through price cuts and exit causes negative profits. When these conditions are fulfilled price always approximates cost even if there is only one firm in the market. So both the existence of economies of scale which deters entry and the faster price changes could be ruled out (Green, 1987:485).

\subsection{Paradigms as Policy Alternatives in EU and USA}

The mainline paradigm, alternative paradigm, and the contestable market theory are also questioned in empirical grounds and advocates of these approaches are still trying to justify their views. In the meantime, the search for a tenable economic case for an activist competition policy is weakening as a result of increasing international competition. The activities of the multinationals are going far beyond national competition laws and regulations. For instance, the mergers and take overs which are taking place especially after the second half of 1980 s following what we can call a "merger-mania" in the United States, which has started during the Reagan administration and which reflects the president's hands-off philosophy of business regulation, constitutes a remarkable example of the changing trends in the world. The developments in the United States concerning antitrust regulations and their enforcement are important in the sense that United States experience of antitrust creates an example for the mature phase of competition policy in the European Union. It is widely argued that the completion of the internal market has brought about the need for a reexamination of the basis of EU competition policy. There is also a widely held belief that the most appropriate model for that reexamination is the Chicago based neoclassical model, as developed by the enforcing agencies, some courts, and many influential commentators in the United States (Frazer, 1990).

\section{Four Main Propositions for the Purpose, Scope and Implementation of Competition Policy}

There is a widely accepted belief that the existence of an effective competition policy is a precondition for a successful market economy. The need for such a policy was recognized since 1776 as mentioned above, together with the publishing of the famous book of Adam Smith, The Wealth of Nations. The main issue is that a market can be manipulated to have greater economic power by entrepreneurs or companies and this may result in the distortion of economic efficiency and competition. There 
are also political, ethical, social issues in question in the absence of competition. There are, currently, four main propositions outlined by economists and policy makers about the purpose, scope, and implementation of competition policy from view point of existing policies of United States, European Union, and other developed countries in the world (Hay, 1996:73).

First, the ultimate goal of competition policy should be economic efficiency. Second, economic analysis is not clear about efficiency effects of particular market structures and conduct. Third, the success of competition policy depends on the concrete design of policy and policy institutions. Fourth, international harmonization of competition policies is a crucial step in the making, together with the establishment of a supranational competition authority. These four propositions summarize the current views concerning a sound competition policy in the world. The first and the second propositions involve the main economic paradigms discussed above and their policy implications as a world trend. The third proposition constitutes one of the core ideas of the present paper. Turkey has a Competition Act but the policy design and its institutions are still to be made. The fourth proposition highlights an advanced stage in terms of the implementation of competition policy. The main concern is the harmonization of rules on the international level. Next, there could be a potential conflict between general industrial policy and the competition policy. The EU and USA are now at the last stage, creating agreements between themselves and under the nearly universal structure of World Trade Organization in the short-run. The concept of globalization, regional economic integration processes and the growing number of multinational companies bring about a global policy implication, the soundness of which will depend on the international harmonization of competition rules.

\section{Questioning the Case of Turkey}

Taking all the above mentioned theoretical basis and facts concerning the changing trends in competition policy into account, it is believed that the following questions are needed to be answered in the case of Turkey. Should Turkey have an industrial policy? What type of an economic approach should be chosen for a sound competition policy in Turkey? What would be the possible competitive effects of customs union with EU? Unfortunately, governmental and nongovernmental institutions, the private sector, workers unions, etc. have started from the last question and they still continue to do so. It is clear that Turkey has missed successive industrial revolutions in the world. Therefore, Turkey urgently needs to have an industrial policy and depending on this, Turkey is in need of a technology policy and also a sound competition policy. While realizing these goals, there is, undoubtedly, a need for taking into account the interaction of the national economy with the international economy. It is clear that liberal economic approach is against industry policy since it means 
government regulation, but at this stage Turkey needs to consider these from a rather radical and pragmatic point of view. The economic ground for the competition policy, in the case of Turkey, is an important issue since the policy implications of the choice is extremely serious. A brief insight to the economic history of Turkey since the establishment of Republic presents the policy maker with an outline concerning the structure of the Turkish industry and foundations of it. The State has always been the main initiator in the creation of private sector and the industry, however, it should leave the leading role to the private sector and the private sector should learn to stand on its on feet. The liberalization movement of the 1980s started the necessary process to a certain extent, but these is a long way to go still. The privatization trend which started to take a considerable pace this year leads to private monopolies or unefficient use of resources, and it should be affirmed by a sound industrial and competition policy in order to catch the international standards. It is believed that the mainline approach which mainly focuses on market power, could be more suitable to meet Turkey's needs at the initial stage, and the regulations should be made accordingly. Since Turkey is still believed to go further in the making of a mature phase of liberal free-market economy and lacks certain necessary structuring and optimal regulations, the Chicago model which is based on market efficiency might create undesired results and Turkey would be facing increasing number of monopolies reducing the consumer welfare, moreover, leading to misallocation of resources. If one looks at the evolution of the EU competition policy, it is possible to see the same. EU has started to consider a Chicago based model for its competition policy after 1990s, they have first monitored the developments in the United States. In an article published in The Economist it is argued that ${ }^{3}$, by March 1995, 95 mergers were notified to the Commission under European competition laws and only six of them were subjected to detailed scrutiny. This compares with 58 mergers the previous year, and a mere dozen in 1990. It seems that the Competition Directorate of the European Commission (DGIV) has been taking a relaxing stance; the number of antitrust cases launched by the Commission fell from twenty-seven in 1993 to sixteen in 1994. On the other hand, in the United States, the number of possible monopolies scrutinized by the Justice Department's antitrust division rose from three in 1992 to twenty-two in 1994. Merger and restraint-ol-trade investigations have also risen sharply. A brief insight to the statistical overview of the 25th Report on Competition Policy issued by DGIV of the EU Commission covering the developments of the year 1995, reflects, in a way, the effect of United States trend of competition policy over EU policy. In the year 1995, the Commission registered 559 cases, including 368 notifications, 145 complaints, and 46 cases opened on the Commission's new initiative. This represent increase which is more than $\% 42$ in comparison with the year 1994, and exceeds the 
average number of incoming cases over the last eight years by more than $\% 32$ (25th Report, 1995:37). Apart from this, it is known that the year 1995 marked a further step in terms of the EU competition policy. The DGIV has prepared a report in July 1995 making a number of recommendations concerning the new trade order in the world and strenghtening international cooperation and the rules (COM (95) 359). This included a bilateral cooperation with United States in the field of competition policy and also a pluralistic international cooperation agreement setting the minimum denominator. Another, significant development took place on June 1996, a communication was adopted by the Commission to the Council on trade and competition jhich addresses the "problem of anti-competitive practices hindering effective access to foreign markets" (Newsletter, Summer 1996:46). The reason behind the adoption of such a communication was to clarity the EU position for the World Trade Organization Ministerial Meeting in Singapore at the end of 1996. The WTO was chosen as an international forum in the preparation of an international framework of competiton rules, and the work to this end still continues. On the other hand, in 1994 Turkey has adopted a new Act on competition on the eve of customs union with EU, which in itself more or less an adoption of the EU competition policy rules, the articles 85 and 85 of the Rome Treaty. Together with this new code, there is a Competiton Council to be established in order to fill in the outline provided by the code and to implement an activist competiton policy. Unfortunately, since 1994, the establishment of the Council is not realized and this is believed to harm only Turkey. In the Report issued on October 1996 bmy the EU Commission concerning the developments between Turkey and EU since the entry into force of the Customs Union, it is stressed that "non-establishment of an authority to monitor compliance with competiton law... pose no threat to the functioning of the customs union, ... do greater harm to Turkish than Community interests, the Commission finds them regrettable" (COM (96) 491 final:2).

The possible competitive effects of customs union with EU is one of the most important topics which continues to be discussed by nearly all segments of the Turkish society. The question is, what are the advantages and disadvantages of customs union concerning our market system and industry? And, there are various arguments about it but two of them mainly holds the agenda. First argument is that customs union will increase competitiveness and will gear considerable amount of investments to Turkish market. The initial answer of the foreign investors to the issue is far from being promising, in fact. For instance, the general manager of Siemens Turkey in a special supplement of Financial Tumes" says that Siemens will be effected by the free competitive environment that will take place in Turkey as much as the other firms. So they have made a joint venture with Bosch and bought the majority of the 
shares of Profilo Holding, one of the leading producer of household electrical appliances, and via such move they plan to step on the Turkish market on a firm basis. This type of development cannot realy be said to be in tune with the great expectations out of the customs union, especially in the short run, since the expectations were in the direction of attracting foreign capital and technology know-how to Turkey. The second argument is that especially Turkish medium and small scale industries will be affected rather badly because of free competition in the short run. If the necessary projects concerning their financing are not prepared on time, it is most likely that they will not be able to face hard competition. One important issue in this respect is first to define the business volume of a small or medium scale industry according to EU standards since there is a definite difference between the two and then to prepare feasible projects for financing them.

In brief, Turkey has entered into customs union with EU despite all the advantages and disadvantages which could be discussed through many more pages. At this stage it is appropriate to sum up main suggestions as a whole. First, Turkey should try to develop an industry policy, the emphasis of which should be on the planning techniques and on efforts directed to the medium-term and long-term organization of the economy. The focus should be on the strategic development of industry as an interrelated whole, and the need to direct or encourage the movement of resources into key areas. Next, if the industry policy is realized in such a way and completed with a sound competition policy, and a technology policy the projected possible negative effects of the customs union could be turned into positive effects in the medium and long terms. These are vital issues, since, especially, the information technology brings a remarkable perspective to the notion of globalization. Third, Turkey could possibly meet increasing international competitiveness in an optimal way with sound policies and policy institutions. Finally, the definition and implementation of a competition policy is a matter of political choice so it should be addressed at a political level but the emergence of the tension between free competition and protectionism could be predicted as an EU or a general concern for us all. 


\section{BIBLIOGRAPHY}

Alchian, A. and Demsetz, H.,

1972 "Production, information costs and economic organization", American Economic Review, 62, pp. 777-795.

Baumol, W., Panzar, J., Willig, R.,

1982 Contestable Markets and the Theory of Industry Structure, San Diego: Harcourt Brace.

Commission of European Communities

1995 European Community Competition Policy, 25th Report on Competition Policy, DGIV, Brussels.

1996 Competition Policy Newsletter, Vol.2, No.2, Summer 1996, DGIV, Brussels.

1996 Report on Developments in Relations with Turkey since the Entry Into Force of the Customs Union, (COM (96) 491 Final), Brussels.

The Economist,

1995 "Antitrust in America and Europe: Off-Line", 27 May 1995, p. 69.

Ferguson, P.R.

1989 Industrial Economics: Issues and Perspectives, London: Macmillan.

Financial Times,

1996 "Turkey and Customs Union", Special Supplement, 22 January 1996.

Frazer, T.

1990 "Competition Policy after 1992: The Next Step", The Modem Law Review, 53, No. 5, September 1990, pp. 352-74.

Green, C.

1987 "Industrial Organization Paradigms, Empirical Evidence, and the Economic Case for Competition Policy", Canadian, Joumal of Economics, 20, No. 3, August 1987, pp. 482-505.

Hay, D.

1996 "Competition Policy" in Readings in Microeconomics, ed. T. Jenkinson, Oxford University Press.

McKie, J.W.

1970 "Market Structure and Function: Performance versus Behavior" in Industrial Organization and Economic Development; Essays in Honour of Edward Mason, J.W. Markham and G.F. Papanek (eds.), Houflon Mifflin. 
McNully, $P$.

1968 "Economic Theory and the Meaning of Competition", The Quarterly Joumal of Economics, 82, November 1968, pp. 639-650.

Stigler, $\mathrm{G}$.

1957 "Perfect Competition Historically Contemplated", Five Lectures on Economic Problems, London School of Economics.

1968 The Organization of Industry, Homewood, Illinois: Richard Irwin Inc. 